vol.6. No. 2 - 2019

\title{
EVALUATE NURSE PHYSICIAN RELATIONSHIP AND ITS IMPACT ON THEIR PERCEPTION OF NURSE ROLE $1^{\text {st }}$ Dina Mohamed Hamed $2^{\text {nd }}$ karima Ahmed Elsayed, $3^{\text {rd }}$ WafaaMostafa Mohamed Soliman

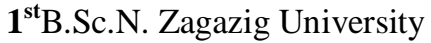 \\ $2^{\text {nd }}$ Assistant Professor of Nursing Administration Faculty of nursing Tanta University , $3^{\text {rd }}$ Lecturer of Nursing Administration Faculty of nursing Zagazig University \\ Email:dabdoba98@yahoo.com
}

\begin{abstract}
Background: Nurse-physician relationship is particularly important, given the interdependence of the two professions and the primary role they play in safe, quality patient care. The well-entrenched hierarchical authority structure and sexism complicate nurse-physician relationship . Unfortunately, disruptive communication occurs with alarming frequency in both nurses and physicians, and both sets of professionals agree that such ways of communicating decrease patient safety. Aim of the study: To evaluate nurse physician relationship and its impact on their perception of nurse`s role. Subjects and method: A descriptive design was used to carry out this study. The study was conducted at El-Mansoura Health Insurance hospital study subjects were included all 250nurses and all 100physicians. One tool was called nurse physician relationship and its impact on their perception of nurse role questionnaire sheet. Results and Conclusion: The finding of the present study indicated that physicians scored higher mean score related to nurse physician relationship than nurses. The level of nurse physician relationship from the majority of physicians and the nurses was moderate. Recommendation: improving collaborative relationship between nurses and physicians through Understand each other's roles.
\end{abstract}

Key words: Nurse physician relationship ,Perception of nurse role.

\section{Introduction}

There is growing of chronic and complex illness recognition that no single professional can manage the increased prevalence treated in the. This has stimulated global interesting nurse physician relationship to deliver safe, efficient and cost-effective care (McInnes et al., 2015).

The importance of nurse physician relationship as a means of having the right health professional providing the right care at the right time for consumers. While, collaboration between health professionals has been shown to improve care coordination, enhance client outcomes and reduce healthcare costs. It is predicated on a clear understanding of each team member's role. Poor role clarity is reported in the literature as a costly barrier to effective cooperation (Besner et al., 2013).

Nurse-physician relationship is particularly important, given the interdependence of the two professions and the primary role they play in safe, quality patient care. The well-entrenched hierarchical authority structure and sexism complicate nurse-physician relationship . Unfortunately, disruptive communication occurs with alarming frequency in both nurses and physicians, and both sets of professionals agree that such ways of 
communicating decrease patient safety

(Robinson, 2012).

Patient advocacy and ethical decisionmaking are primary nursing responsibilities, and the trust of the public is invested in nurses as advocates and as patient-family-physician communication mediators. Limited autonomy and problematic nurse physician relationship in critical care may be associated with the limited authority of nurses to apply their personal and professional moral reasoning and values in the care of patients. This may lead to individual nurses experiencing greater moral distress. Furthermore, Moral distress is linked with burnout and job fatigue(Maiden et al., 2015).

Where there is role ambiguity, nurses often express frustration and report increased incidences of work place dissatisfaction and conflict . Nurses' role ambiguity means lack of clarity in their scope of practice. While role clarity is reported to facilitate cooperation, role optimization and professional identity (Almost et al., 2016).

There are multiple pressures associated with clinical workload, practice ownership, employee contracts, regulatory demands and inter professional relationships (Sinsky et al., 2013). Despite these stressors and the perceived benefits of cooperation, there is little evidence to suggest that general practitioners cooperate with nurses to capitalize on available expertise in this dynamic environment. The rapid growth in the general practice nurse workforce was largely brought about by Federal government policies which provide financial incentives to employ practice nurses (McInnes et al., 2015).

Where nurses are once viewed as general practitioners assistants, they now play a central role in managing chronic disease, facilitating lifestyle risk factor modification and supporting acute health issues across the life span. However, there has been limited attention focused on how this clinical role integrates with the care provided by general practitioners, or the impact of the growth in the general practice nursing workforce on the inter professional relationships in this setting .Such changes have create significant shifts in ways of working and the need for health professionals to work both with others from their own profession and with other health professionals (McInnes et al., 2015).

Disruptive behaviors of the medical team are unacceptable manner in the workplace. Many institutes try to improve the behavior of their team by educating and training them to enhance effective communication and cooperation skills and to reduce adverse consequences, because healthcare professionals are directly associated with the outcomes of patients. Despite these efforts, physicians' and nurses' disruptive behaviors is common in health care settings (Longo, 2013).

Nurses' role in primary care has recently received substantial scrutiny, as demand for primary care has increased and nurse practitioners have gained traction with the public. A study indicated that primary care services, such as wellness and prevention services, diagnosis and management of many common uncomplicated acute illnesses, and management of chronic diseases such as diabetes can be provided by nurse practitioners at least as safely and effectively as by physicians. After reviewing the issue, an Institute of Medicine (IOM) panel recently repeated this conclusion and called for expansion of nurses' scope of practice in primary care(Fairman, 2014). 


\section{Significance}

Relationship between nurses and physicians is important to study because how well these two groups work together affects the quality of care that patients receive. Collaborative nurse-physician relationship also leads to better patient and organizational outcomes such as decreased length of stay and reduction in treatment costs without reduction in functional levels or decrease in satisfaction among patients. In addition to patient outcomes, highquality nurse-physician relationships result in increased satisfaction among nurses and physicians and increased autonomy for nurses. (Schmalenberg\& Kramer2009).

\section{Collaboration,}

clear communication, cooperation, respect, and positive attitudes are the essential ingredients for any relationship. Shared positive attitude and behavior is what will drive a team to be successful. Doctors and nurses need to function at an emotionally intelligent level.

\section{Aim of the Study}

To evaluate nurse physician relationship and its impact on their perception of nurse`s role.

\section{Research Questions}

1-What is the level of nurse physician relationship?

2-what are the perception of nurse and physician toward nurse role?

\section{Subjects \& Methods}

\section{Study Design:}

A descriptive correlational design was used to carry out this study.

\section{Setting}

This study was conducted at Mansoura Health insurance hospital which contains 6 floors and includes 300 beds which distributed as the following: (The emergency department 12 beds, surgical intensive care unit 8 beds, urinary tract department 24 beds, obstetrics and gynecology, 24 beds, Cardiac intensive care unit 7 beds, surgical department (A) 24 beds, surgical department( B) 24 beds, special surgeries department 24 beds, children department 24 beds, orthopedics department 24 beds, nose and ear department 24 beds, medical department 24 beds, hematemesis department 24 beds, premature unit 10 incubators, economic department 10 beds, and hemodialysis unit 12 beds).

Subjects

Study subjects included all nurses about (250) working in El-Mansoura Health Insurance Hospital at the time of the study and all the physicians about (100) working in the same time of the study.

Tool of Data Collection: Data were collected through questionnaire sheet developed by the researcher guided by the relevant literature (Christman, 1998; Gianakos, 1997, Sweet \& Norman, 1995 and Abdelmotleb 2004)

This tool consists of two parts: First part

Concerning the characteristics data of nurses / physicians, such as age, gender, education, job, experience, and departments

\section{Second part}

It included 67 items this tool aims to evaluate nurse - physician relationship and the participants' perception of nurse's role.

This tool was grouped into five dimensions as followed Interpersonal relationship included 22 items, Work stress included5 items, Job performance included 7 items, Administrative policies and norms included 14 items and Perception of nurse's role included 19 items.

\section{Scoring system}

Subject's responses were measured on a Five-point Likert Scale as follow, Strongly agree scored (5), agree scored( 4), neutral scored (3), disagree 
scored (2), and strongly disagree scored (1).Levels of nurse physician relationship are classified into three levels ; high $>75 \%$ ,moderate $60-75 \%$ and low $<60 \%$.

\section{II- Operational design}

The operational design includes the preparatory phase, pilot study, implementation phase.

\section{Preparatory phase}

This phase-involved review of literature related to the problem, and aim to acquire theoretical knowledge of related administrative principles, using books, magazines, and internet in order to develop data collection tool. Also, this phase was concerned with translation, validation and preparation of tool for data collection with managerial arrangements to carry out the implementation phase.

\section{Validity}

The tool was distributed to a jury group of five experts three professors and two assistant professor from Faculty of Nursing at Zigzag University to judge content validity of tools. Each one of them was handed a questionnaire package into English and Arabic to review, clarity, relevancy, applicability, comprehensiveness, understanding, and ease for implementation. The period taken by the jury group lasted from the end of march to the end of April2017 modifications were done based on opinions of experts.

\section{Reliability of data collection tool}

The reliability of the tool was reported by the original authors by suitable statistics . Cronbach's Alpha was $\mathbf{0 . 8 3 3}$ nurse physician relationship and their perception of nurse role.

\section{Field work}

Field work of the current study was excited in three months started at the beginning from the end of May to the end of July combing the information two days a week and two hours per day between three shift . The researcher used a code number to mark each sheet using systematic serial number for each units. Personal interviews with the study subjects either nurses or physicians were done at different days according to their work attendance schedule to fill the study questionnaire

\section{Ethical consideration}

Official permission to conduct the study obtained from the Dean of the faculty of nursing. Formal approval obtained from the research ethics committee of the Zigzag University faculty of nursing. Oral informed consents were obtained from the participants. Privacy and confidentiality of the collected data will be assured and participants were able to withdraw from the study at any stage without responsibility.

\section{Pilot study}

A pilot study was carried out to test the tool feasibility, clarity, and to estimate the time consumed for filling in the forms. A brief explanation of the purpose of the study and then provided every participant .with a copy each of the study tools. The pilot study was carried out on $10 \%$ of the subjects (25 nurse and 10 physician) from Mansoura Health Insurance Hospital The time consumed in answering the tool were about (20 -30minites). This data collected from the pilot study were reviewed and modificated to the items prior to the final application on the study .

\section{Statistical Design}

After complete data collection ,the data were organized and tabulated ,statistically analyzed using both Epi-Info 6.04 computer software package and SPSS version 20.0 statistical software .,Data were presented using descriptive statistics in the form of frequencies and percentages for qualitative variables, and means and standard deviations for quantitative variables. 
EVALUATE NURSE PHYSICIAN RELATIONSHIP etc...

Results

Table(1):Levels of perception of physicians and nurses regarding nurse physician relationship and their perception of nurse role

\begin{tabular}{|c|c|c|c|c|c|c|c|c|}
\hline \multirow{2}{*}{ Domains } & \multirow{2}{*}{ Items } & \multicolumn{3}{|c|}{ Physicians (100) } & \multicolumn{3}{c|}{ Nurses (250) } & Significance \\
& & Low & Moderate & High & Low & Moderate & High & test \\
\hline $\begin{array}{c}\text { Physician nurse } \\
\text { relationship }\end{array}$ & No & 3 & 89 & 8 & 13 & 220 & 17 & $\chi^{2}=0.908, \mathrm{P}$ \\
& $\%$ & 3.0 & 89.0 & 8.0 & 5.2 & 88.0 & 6.8 & 0.635 \\
\hline \multirow{2}{*}{ Work stress } & No & 7 & 16 & 77 & 18 & 39 & 193 & $\chi^{2}=0.012, \mathrm{P}$ \\
& $\%$ & 7.0 & 16.0 & 77.0 & 7.2 & 15.6 & 77.2 & 0.994 \\
\hline Job performance & No & 1 & 57 & 42 & 5 & 170 & 75 & $\chi^{2}=4.826, \mathrm{P}$ \\
& $\%$ & 1.0 & 57.0 & 42.0 & 2.0 & 68.0 & 30.0 & 0.092 \\
\hline Administration & No & 42 & 55 & 3 & 111 & 128 & 11 & $\chi^{2}=0.641, \mathrm{P}$ \\
policies & $\%$ & 42.0 & 55.0 & 3.0 & 44.4 & 51.2 & 4.4 & 0.726 \\
\hline \multirow{2}{*}{ Nurses' role } & No & 0 & 34 & 66 & 0 & 49 & 201 & $\chi^{2}=8.187, \mathrm{P}$ \\
& $\%$ & 0.0 & 34.0 & 66.0 & 0.0 & 19.6 & 80.4 & $0.0044^{*}$ \\
\hline \multirow{2}{*}{ Total Score } & No & 0 & 91 & 9 & 0 & 233 & 17 & $\chi^{2}=0.908, \mathrm{P}$ \\
& $\%$ & 0.0 & 91.0 & 9.0 & 0.0 & 93.2 & 6.8 & 0.635 \\
\hline
\end{tabular}

Significant at $(\mathrm{p}<0.05)$

Table (1) illustrates that there is no significant differences all domains except items nurse role $(\mathrm{p}>0.05)$. The majority of nurses and physicians had moderate level regarding physician nurse relationship and its impact on their perception of nurse role

.The majority of nurses and physicians had moderate level regarding physician nurse relationship ,job performance and administration policies. The majority of nurses and physicians had highest level regarding work stress and nurse role.

Table (2):Perception of physicians and nurses regarding nurse physician relationship and their perception of nurse role

\begin{tabular}{|c|c|c|c|c|c|}
\hline \multirow{2}{*}{ Domains } & \multicolumn{2}{|c|}{ Physicians (100) } & \multicolumn{2}{|c|}{ Nurses (250) } & \multirow{2}{*}{ Significance test } \\
\hline & Mean & \pm SD & Mean & \pm SD & \\
\hline $\begin{array}{l}\text { Physician nurse } \\
\text { relationship }\end{array}$ & 3.43 & 0.23 & 3.35 & 0.30 & $\mathrm{t}=2.381$, P0.018 \\
\hline Work stress & 3.85 & 0.44 & 3.82 & 0.45 & $\mathrm{t}=0.384, \mathrm{P0} .487$ \\
\hline Job performance & 3.79 & 0.17 & 3.72 & 0.25 & $\mathrm{t}=2.292, \mathrm{P0.022}{ }^{*}$ \\
\hline $\begin{array}{l}\text { Administration } \\
\text { policies }\end{array}$ & 3.04 & 0.39 & 3.05 & 0.51 & $\mathrm{t}=0.222, \mathrm{P0.824}$ \\
\hline Nurses' role & 3.81 & 0.19 & 3.87 & 0.29 & $\mathrm{t}=2.267, \mathrm{P} 0.024^{*}$ \\
\hline Total Score & 3.52 & 0.15 & 3.50 & 0.17 & $\mathrm{t}=1.061, \mathrm{P} 0.290$ \\
\hline
\end{tabular}

Significant at $(\mathrm{p}<0.05)$

Table (2) illustrates that both physicians and nurses had the same mean scores regarding perception of physicians and nurses regarding nurse physician role. There is a significant differences in three domains of Physician nurse relationship, Job performance and nurses' role $(\mathrm{p}<0.05)$. 
Dina Mohamed Hamed et. al.

Table (3):Relation between physician perception related to nurse physician relationship and their perception of nurse role and their characteristics. $(n=100)$

\begin{tabular}{|c|c|c|c|}
\hline \multirow{2}{*}{ Characteristics } & \multirow{2}{*}{ Items } & \multirow{2}{*}{ No } & Perception score \\
\hline & & & Mean \pm SD \\
\hline Age (years) & $\begin{array}{l}20- \\
30- \\
40- \\
50+\end{array}$ & $\begin{array}{c}10 \\
68 \\
19 \\
3\end{array}$ & $\begin{array}{l}3.43 \pm 0.22 \\
3.56 \pm 0.14 \\
3.45 \pm 0.11 \\
3.33 \pm 0.02\end{array}$ \\
\hline \multicolumn{3}{|c|}{ Significance test } & $\mathrm{F}=5.752, \mathrm{P} 0.001^{*}$ \\
\hline Gender & $\begin{array}{c}\text { Males } \\
\text { Females }\end{array}$ & $\begin{array}{l}89 \\
11\end{array}$ & $\begin{array}{l}3.51 \pm 0.16 \\
3.56 \pm 0.13\end{array}$ \\
\hline \multicolumn{3}{|c|}{ Significance test } & $\mathrm{t}=0.895, \mathrm{P} 0.373$ \\
\hline Education & $\begin{array}{c}\text { MBBcs } \\
\text { Master } \\
\text { MD }\end{array}$ & $\begin{array}{c}26 \\
68 \\
6\end{array}$ & $\begin{array}{l}3.50 \pm 0.19 \\
3.54 \pm 0.14 \\
3.40 \pm 0.11\end{array}$ \\
\hline \multicolumn{3}{|c|}{ Significance test } & $\mathrm{F}=2.292, \mathrm{P} 0.106$ \\
\hline Job & $\begin{array}{c}\text { Resident } \\
\text { Specialist } \\
\text { Consultant }\end{array}$ & $\begin{array}{c}21 \\
71 \\
8\end{array}$ & $\begin{array}{l}3.48 \pm 0.22 \\
3.54 \pm 0.14 \\
3.43 \pm 0.11\end{array}$ \\
\hline \multicolumn{3}{|c|}{ Significance test } & $\mathrm{F}=2.912, \mathrm{P} 0.059^{*}$ \\
\hline $\begin{array}{l}\text { Experience } \\
\text { (years) }\end{array}$ & $\begin{array}{c}<5 \\
5- \\
10- \\
15+\end{array}$ & $\begin{array}{c}5 \\
26 \\
43 \\
26\end{array}$ & $\begin{array}{l}3.34 \pm 0.10 \\
3.54 \pm 0.19 \\
3.55 \pm 0.13 \\
3.48 \pm 0.13\end{array}$ \\
\hline \multicolumn{3}{|c|}{ Significance test } & $\mathrm{F}=4.371, \mathrm{P} 0.006^{*}$ \\
\hline Departments & $\begin{array}{l}\text { Medical } \\
\text { Surgical }\end{array}$ & $\begin{array}{l}37 \\
63\end{array}$ & $\begin{array}{l}3.50 \pm 0.20 \\
3.53 \pm 0.13\end{array}$ \\
\hline \multicolumn{3}{|c|}{ Significance test } & $\mathrm{t}=0.722, \mathrm{P} 0.472$ \\
\hline
\end{tabular}

Significant at $(\mathrm{p}<0.05)$

Table (3) shows that there were statistical significant differences between physicians' perception scores, age, job and experience $(\mathrm{p}<0.05)$. The result shows that physicians were in age group from 20 to less than 30 , female, who had master degree, specialist physicians and who had 10 to less than 15 years of experience had high level of perception regarding nurse physician relationship and their perception of nurse role. 
EVALUATE NURSE PHYSICIAN RELATIONSHIP etc...

Table (4): relation between nurses perception related to nurse physician relationship and their perception of nurse role and their characteristics

\begin{tabular}{|c|c|c|c|}
\hline \multirow{2}{*}{ Characters } & \multirow{2}{*}{ Items } & \multirow{2}{*}{ No } & Perception score \\
\hline & & & Mean \pm SD \\
\hline \multirow[t]{3}{*}{ Age (years) } & $20-$ & 140 & $3.49 \pm 0.16$ \\
\hline & $30-$ & 107 & $3.52 \pm 0.18$ \\
\hline & $40+$ & 3 & $3.454 \pm 0.03$ \\
\hline \multicolumn{3}{|c|}{ Significance test } & $\mathrm{F}=1.515, \mathrm{P} 0.222$ \\
\hline \multirow[t]{2}{*}{ Gender } & Males & 74 & $3.49 \pm 0.16$ \\
\hline & Females & 176 & $3.51 \pm 0.18$ \\
\hline \multicolumn{3}{|c|}{ Significance test } & $\mathrm{t}=0.985, \mathrm{P} 0.353$ \\
\hline \multirow[t]{4}{*}{ Education } & Nursing & 152 & $3.50 \pm 0.18$ \\
\hline & diploma & 48 & $3.47 \pm 0.08$ \\
\hline & Tech. Institute & 50 & $3.56 \pm 0.21$ \\
\hline & $\begin{array}{l}\text { Bachelor's } \\
\text { degree }\end{array}$ & & \\
\hline \multicolumn{3}{|c|}{ Significance test } & $\mathrm{F}=3.543, \mathrm{P} 0.030^{*}$ \\
\hline \multirow[t]{3}{*}{ Job } & Nurse & 152 & $3.50 \pm 0.18$ \\
\hline & Technical nurse & 48 & $3.47 \pm 0.08$ \\
\hline & Nurse specialist & 50 & $3.56 \pm 0.21$ \\
\hline \multicolumn{3}{|c|}{ Significance test } & $\mathrm{F}=3.543, \mathrm{P} 0.030^{*}$ \\
\hline \multirow{4}{*}{$\begin{array}{c}\text { Experience } \\
\text { (years) }\end{array}$} & $<5$ & 21 & $3.44 \pm 0.19$ \\
\hline & $5-$ & 114 & $3.50 \pm 0.15$ \\
\hline & $10-$ & 82 & $3.52 \pm 0.19$ \\
\hline & $15+$ & 33 & $3.54 \pm 0.18$ \\
\hline \multicolumn{3}{|c|}{ Significance test } & $\mathrm{F}=1.535, \mathrm{P} 0.0206$ \\
\hline \multirow[t]{2}{*}{ Departments } & Medical & 85 & $3.48 \pm 0.19$ \\
\hline & Surgical & 165 & $3.52 \pm 0.17$ \\
\hline \multicolumn{3}{|c|}{ Significance test } & $\mathrm{t}=0.932, \mathrm{P} 0.374$ \\
\hline
\end{tabular}

Table (4) shows that there were statistical significant relation differences between nurses' perception scores, education and job $(\mathrm{p}<0.05)$. The result reveals that nurses who had Bachelor's

\section{Discussion}

Medicine and nursing are two entitles which have contribution in health care leadership and in marketplace. Hospitals improve reimbursement and be market share when healthy nurses and physicians interprofessional relationships is achieved which in turn reflect on quality care(Tracy \&Grady,2018). degree and nurse specialist had higher mean scores related to nurse physician relationship and their perception of nurse role and their characteristics.

As regard Perception of physicians and nurses regarding nurse physician relationship and their perception of nurse role .This study revealed that, understanding nurse's role was the highest dimension mean score, while relationship was the lowest dimension mean score among nurses and physicians' perceptions. The reason behind this may be due to that 
nurses and physicians were appreciated, and understand each other's role. Indeed, most nurses and physicians agreed that the role of nurses is important as well as that of physicians in the health care team. Moreover, a nurse's role is limited to the implementation of physicians' instructions as well as providing direct patients care.

This finding goes with Robinson, (2012) who stated that both nurses and physicians perceived highly in the understanding of each other's role and nurses were satisfied with their role regarding carrying out physicians' orders and patient care. Furthermore, those physicians believe that their role is the most important role in the health care team.

This result was opposite to Koff, et al., (2012) who pointed out that there is a lack of understanding about the unique professional role of nurses, leading to ineffective collaboration between physicians and nurses. Nurses were often perceived by physicians to be only responsible for carrying out their treatment orders and nurses, who have frequent contact with patients and family members, could actually con-tribute more to patient care by offering their perspectives and participate in decision-making. However, physicians tend to have minimal insights into these roles of nurses and this could be observed through certain dismissive words or behaviors they exhibit.

As regard perception of physicians and nurses regarding the nurses' role and its effect on their relationship .The study revealed that nurses had the highest mean scores related to perception about the nurses' role and its effect on their relationship. This is due to nurse can make decision about patient nursing care independently and nurse's role includes teaching new nurses in the unit and observes their performance.

The finding was also similar with Getachew et al., (2014) who found that physicians had the lowest mean scores in the perception of nurse's role. This finding was accordance with Schmalenberg \& Kramer,(2010) who found that physicians had higher mean scores than nurses and can trust that nurses will do and see that patients get what they need they also are great at interpreting what the patient is trying to tell them. This result similar with Elithy et al.,(2013)who showed that the nurses higher mean score than physicians were found in understanding each other role and communication. The finding was supportedby Mohsen et al., (2017) who stated that limited knowledge of nursing roles negatively affects the physicians' willingness to practice collaboration. Regarding relation between physician perception related to nurse physician relationship and their perception of nurse role and their characteristics. The result shows that physicians were in age group from 20 to less than 30 , female, who had master degree, specialist physicians and who had 10 to less than 15 years of experience had high level of perception regarding nurse physician relationship and their perception of nurse role.

The result was opposite with. Marklund et al.,(2019) who revealed that There was no difference between younger and older, male and female physicians regarding nurse physician collabporation .

Regarding relation between nurses perception related to nurse physician relationship and their perception of nurse role and their characteristics. The result shows that the nurses perception related to nurse physician relationship and their perception of nurse role and their 
characteristicswere high in age from 30 to less than 40 , in female than male, who had Bachelor's degree, nurse specialist and with who had more than 15 years of experience in all departments(medical and surgical).

The finding goes with Parro et al., (2013) who stated that nurses with Degree's or Postgraduate studies in Nursing have a preferable perception of the overall perception of nurse physician relationship .The result was similar with Johnson, S. \&Kring, D. 2012. Who revealed that, more than half of ICU and Medical-Surgical nurses reported they satisfied with the nurse-doctor relationships .

The result was opposite to Hussein(2018) who revealed that there was no significant difference in nurses' perception of male and female respondents, there was no significant difference between the diploma holder and degree holder . there was no significant difference between working experience less than 10 years and working experience of more than 10 years and there is no significant difference between working experience and nurses' perception toward the nurse-doctor relationship

\section{Conclusion}

The majority of nurses and physicians had moderate level regarding physician nurse relationship and its impact on their perception of nurse role there is no significant differences all domains except items nurse role $(p>0.05)$. The majority of nurses and physicians had moderate level regarding physician nurse relationship, job performance and administration policies. The majority of nurses and physicians had highest level regarding work stress and nurse role.

\section{Recommendations}

Based on the finding of the current study the following recommendations can be suggested to improve nurse physician relationship:

Hospital Administration: Establishing programs to enhance the communication between nurses and physicians through these programs they understand each other's roles and improve the collaborative relationship between them.

.Nurses and physicians: Mutual understanding between nurses and physicians which would enhance coordination and cooperation of the services provided for the patients.

Further research: Study the effect of nurse physician relationship on quality of patient care.

\section{References}

Abdelmotleb.E , the nature of nurse physician relationship and its impact on their perception of nurse . 2004 un published master theses pp 49 .

Almost J, Laschinger HKS.(2016) Workplace empowerment, collaborative work relationships, and job strain in nurse practitioners. J Am Acad Nurse Pract. ;14(9):408-420.

Besner, J., Doran, D., McGillis Hall, D., Giovanetti, P., Girard, F., Hill, W., Watson, L. A systematic approach to maximizing nursing scopes of practice. Available from Ottawa 2013.: www.cihr.gc.ca.

Christman, L. Advanced practice nursing is the physician's assistant an accident of history a failure of ret. Nurse outlook, 1998; 46 (2) 56-59.

Elithy,A., Harmina,M., and Elbialy,G., Nurses and Physicians Perceptions 
of Their Interprofessional

Relationships at Alexandria MainUniversity Hospital Journal of American Science, 2013;7(12) http://www.americanscience.org

Fairman, Effective Strategies for Achieving Scope of Practice Reform in Pennsylvania. Policy PolitNursPract. 2014: May; 17(2): 99-109.

Getachew

Gebremedhin,

T. BirhanTema,

Wudneh

H.,Gerezgiher B., Haftu B, Nurse - Physician Work Relationships and Associated Factors in Public Hospitals in Tigray Region, Northern Ethiopia, a Cross Sectional Study Greener Journal of Biomedical and Health Sciences 2014 Vol. 1 (1) 001-013.

Gianakos, D. Physician, nurse and collegiality. Nursing out Look(1997); 45 (3), 57-58.

Hussein, A. Relationship between nurses' [1] and physicians' perceptions of organizational health and quality of patient care. 2018, 20(10).

Johnson, S. \&Kring, D.. Nurses' Perceptions of Nurse-Physician Relationships: Medical-Surgical vs. Intensive Care. MedSurg Nursing 2012,21 (6), 343-347.

Koff, M. D., Corwin, H. L., Beach, M. L., Surgenor, S. D., \& Loftus, R. W.. Reduction in ventilator associated pneumonia in a mixed intensive care unit after initiation of a novel hand hygiene program 2012 . Journal of Critical Care, 26(5), 489-495.

Longo J.Combating disruptive behaviors: strategies to promote a healthy work environment 2013.. Online J Issues Nurs. $15(1)$
10.3912/OJIN.Vol15No01Man05. [ CrossRef]

Marklund B, Hansson A, Arvemo T, Gedda B, Mattsson B. Working together--primary care doctors' and nurses' attitudes to collaboration. Scand J Public Health. 2019; 38(1):78-85.

McInnes, S., Peters, K., Bonney, A., \&Halcomb, E. An integrative review of facilitators and barriers influencing collaboration and teamwork between general practitioners and nurses working in general practice 2015. . Journal of Advanced Nursing, 71(9), 19731985.

Maiden J, Bruce HR, Fedullo PF, et al. Impact of nurse-initiated sepsis protocol on compliance with sepsis bundles, time to initial antibiotic administration and in-hospital mortality. J

EmergNurs. 2015;41:130-7. doi: 10.1016/j.jen.2014.12.007. [PubMe d] [CrossRef]

Mohsen S, Ayman E, Mahmoud R: Nurses and Physicians Attitudes toward Nurse-Physician Collaboration: A Survey from Gaza Strip, Palestine. Nursing Research and Practice . Volume 2017, Article ID 7406278, 7 pages https://doi.org/10.1155/2017/74062 78

Parro Moreno, A., Serrano Gallardo, P., FerrerArnedo, C., Serrano Molina, L., de la PuertaCalatayud, M. L., Barberá Martín, A., Morales Asencio, J. M. et al. Influence of sociodemographic, labour and professional factors on nursing perception concerning practice environment in Primary Health 
Care. Atencionprimaria / Sociedad Española de Medicina de Familia y Comunitaria, 2013.45(9), 476-85. doi:10.1016/j.aprim.2012.12.015.

Robinson L: Effective communication improving communication skills in business and relationships2012.Available: http:// www.helpguide.org/mental/effectiv e_commuition_skills.htm

SchmalenbergC and Kramer M NursePhysician Relationships in
Hospitals: 20000 Nurses Tell Their Story American Association of Critical-Care Nurses, 2009. 29:7483.

Sweet, S., \& Norman, I. The nurse-doctor relationship: a selective literature. Jounal of advanced Nursing. 1995; 22, 165-170.

Tracy and Grady, Family Nurse Practitioner- Volunteer at Mission Clinic of Palm Springs. Nurse EducPract. 2018:;14(4):396-402. 